OPEN ACCESS

Edited by:

Walderez Ornelas Dutra,

Federal University of Minas

Gerais, Brazil

Reviewed by:

Luisa Magalhaes,

Universidade Federal de Minas

Gerais, Brazil

Lúcia Maria Da Cunha Galvão,

Federal University of Rio Grande do

Norte, Brazil

${ }^{*}$ Correspondence:

Maykon Tavares de Oliveira

maykontavares@yahoo.com.br

tThese authors share last authorship

Specialty section:

This article was submitted to General Cardiovascular Medicine,

a section of the journal

Frontiers in Cardiovascular Medicine

Received: 08 February 2021 Accepted: 20 April 2021

Published: 20 May 2021

Citation:

Oliveira MT, Sulleiro E, Silva MCd, Silgado A, de Lana M, da Silva JS, Molina I and Marin-Neto JA (2021)

Intra-Discrete Typing Unit TcV Genetic Variability of Trypanosoma cruzi in Chronic Chagas' Disease Bolivian Immigrant Patients in Barcelona

\section{Intra-Discrete Typing Unit TcV Genetic Variability of Trypanosoma cruzi in Chronic Chagas' Disease Bolivian Immigrant Patients in Barcelona, Spain}

\author{
Maykon Tavares de Oliveira ${ }^{1,2 \star}$, Elena Sulleiro ${ }^{3}$, Maria Cláudia da Silva $^{4}$, Aroa Silgado ${ }^{3}$, \\ Marta de Lana ${ }^{5}$, João Santana da Silva ${ }^{6}$, Israel Molina ${ }^{1 \dagger}$ and J. Antônio Marin-Neto ${ }^{2+}$

\begin{abstract}
${ }^{1}$ Department of Infectious Diseases, Vall d'Hebron University Hospital, Universitat Autònoma de Barcelona, PROSICS Barcelona, Barcelona, Spain, ${ }^{2}$ Cardiology Division, Department of Internal Medicine, Medical School of Ribeirão Preto, University of São Paulo, São Paulo, Brazil, ${ }^{3}$ Department of Microbiology, Vall d'Hebron University Hospital, Universitat Autònoma de Barcelona, PROSICS Barcelona, Barcelona, Spain, ${ }^{4}$ Department of Biochemistry and Immunology, Ribeirão Preto Medical School, University of São Paulo, São Paulo, Brazil, ${ }^{5}$ Pharmacy School and Center of Research in Biological Sciences, Federal University of Ouro Preto, Ouro Preto, Brazil, ${ }^{6}$ Fiocruz-Bi-Institutional Translational Medicine Plataform, Ribeirão Preto, Brazil
\end{abstract}

Background: Trypanosoma cruzi has a high rate of biological and genetic variability, and its population structure is divided into seven distinct genetic groups (Tcl-TcVI and Tcbat). Due to immigration, Chagas disease (ChD), caused by T. cruzi, has become a serious global health problem including in Europe. Therefore, the aim of this study was to evaluate the existence of genetic variability within discrete typing unit (DTU) TcV of T. cruzi in Bolivian patients with chronic ChD residing in Barcelona, Spain.

Methods: The DNA was extracted from the peripheral blood of 27 patients infected with T. cruzi DTU TCV and the fragments of the genetic material were amplificated through the low stringency single primer-polymerase chain reaction (LSSP-PCR). The data generated after amplification were submitted to bioinformatics analysis.

Results: Of the 27 patients evaluated in the study, 8/27 (29.6\%) were male and 19/27 (70.4\%) female, 17/27 (62.9\%) were previously classified with the indeterminate clinical form of Chagas disease and 10/27 (37.1\%) with Chagas cardiomyopathy. The LSSP-PCR detected 432 band fragments from 80 to 1,500 bp. The unweighted pair-group method analysis and principal coordinated analysis data demonstrated the existence of three distinct genetic groups with moderate-high rates of intraspecific genetic variability/diversity that had shared parasite's alleles in patients with the indeterminate and cardiomyopathy forms of ChD.

Conclusions: This study demonstrated the existence of a moderate to high rate of intra-DTU TcV variability in T. cruzi. Certain alleles of the parasite were associated with 
the absence of clinical manifestations in patients harboring the indeterminate form of ChD. These results support the need to search for increasingly specific targets in the genome of $T$. cruzi to be correlated with its main biological properties and clinical features in patients with chronic ChD.

Keywords: Chagas disease, Trypanosoma cruzi, DTU TcV, genetic variability, cardiac form

\section{INTRODUCTION}

Chagas disease $(\mathrm{ChD})$ is caused by the hemoflagellate protozoan Trypanosoma cruzi and chronic Chagas cardiomyopathy is the most severe manifestation (1). According to recent data from the World Health Organization (WHO), $\sim 6$ to 7 million people are chronically infected with T. cruzi worldwide, and more than 75 million individuals are at risk of infection (2).

The genetic structure of T. cruzi is currently divided into seven distinct genetic groups, also known as discrete typing units (DTUs), TcI-TcVI, and TcBat $(3,4)$. T. cruzi presents a high rate of biological and genetic variability (5) and these differences may be linked to the main biological parameters of the different strains of T. cruzi, such as geographical distribution and human clinical manifestations of $\mathrm{ChD}$. However, no previous studies have presented sufficient data to confirm effectively such potential correlations (6).

The area of spread of $\mathrm{ChD}$ is wide across the American continent. One of the most notable changes in the epidemiology of parasitic diseases in recent decades is the emergence of $\mathrm{ChD}$ in European countries, and the associated risk of T. cruzi transmission outside endemic areas (7). Europe is currently hosting large immigrant populations, with recent data estimating that immigrant populations represented $8.7 \%$ of the total European population in 2010 (8). The prevalence of $\mathrm{ChD}$ infection in Latin American immigrants living in Europe is estimated in $4.2 \%$, with the highest prevalence among migrants from Bolivia (18.1\%) and Paraguay (5.5\%) (9). Population movement over recent years has led to an increased prevalence of $\mathrm{ChD}$ in these countries, primarily due to high numbers of Latin American immigrants chronically infected with T. cruzi (10).

Although direct vector transmission cannot occur in Europe, $\mathrm{ChD}$ can be transmitted in non-endemic countries via blood transfusion and organs transplantation, or even vertical transmission (9). Measures to control vertical transmission have been designed and implemented in some countries to avoid spreading $\mathrm{ChD}$ in Europe, although these measures have not been shown to be entirely viable (11).

Assessing the real burden and implications for public health of $\mathrm{ChD}$ in European countries is crucial. Therefore, this study aimed to evaluate the intraspecific genetic variability of DTU TcV from T. cruzi in immigrant patients with chronic ChD residing in Barcelona, Spain, and to correlate the genetic differences intra-DTU with the correspondent clinical forms of ChD.

\section{MATERIALS AND METHODS}

\section{Patients and Blood Samples}

Were evaluated twenty-seven patients with ChD infected by DTU $\mathrm{TcV}$ previously genotyped by our group (12). Diagnosis of ChD was confirmed for all 27 patients via two positive serological tests and real-time PCR, according to the WHO recommendations. All patients were clinically evaluated at Vall d'Hebron University Hospital, Barcelona, Spain, between 2015 and 2019. From all patients, $5 \mathrm{~mL}$ of peripheral blood were collected and mixed with an equal volume of guanidine $6 \mathrm{M}$ /EDTA $0.2 \mathrm{M} \mathrm{pH} 8$ (13). The Guanidine-EDTA Blood lysates (GEB) were boiled for $15 \mathrm{~min}$, incubated at room temperature for $24 \mathrm{~h}$, and stored at $4^{\circ} \mathrm{C}$ until use (14).

\section{Extraction of DNA From Blood/Guanidine and EDTA Samples}

DNA was extracted from $200 \mu \mathrm{L}$ of guanidine/EDTA blood (GEB) samples and eluted in $55 \mu \mathrm{L}$ using the NucliSens easyMAG ${ }^{\circledR}$ system (Biomerieux, France), according to the manufacturer's instructions.

\section{Clinical Evaluation of Patients}

The 27 patients with positive serology and real-time PCR for $\mathrm{ChD}$, were clinically evaluated at the Infectious Diseases Division, Vall d'Hebron University Hospital, Barcelona, Spain, through anamnesis, 12-lead electrocardiogram, chest, esophageal, and colon X-rays, and rest transthoracic echocardiography. The patients were classified as having different clinical forms of chronic ChD $(15,16)$.

\section{Intra-DTU TcV Genetic Variability}

To assess the intraspecific genetic variability of the previously genotyped T. cruzi DTU TcV (11) present in the peripheral blood of patients with chronic $\mathrm{ChD}$, low stringency single primer (LSSP-PCR) methodology (17) was performed. To obtain the genetic signature of $T$. cruzi $\mathrm{kDNA}$, the following steps were performed: (A) amplification of the $330 \mathrm{bp}$ fragment specific to T. cruzi kDNA (18). The amplified products were run on a $1.5 \%$ agarose gel $\left(\right.$ Sigma $\left.{ }^{\circledR}\right)$, stained with Syber (Midori Green Advanced DNA Strain, Nippon Genetics Europe Gmbh) and viewed on the Biorad photo documentation platform (Molecular Imager, Gel DOC XR, Imaging System). The 330 bp fragments were removed from the agarose gel, heated to $100^{\circ} \mathrm{C}$, and diluted in ultrapure water at a 1:10 dilution. (B) DNA of the diluted 330 bp band fragments was subjected to a new amplification cycle using the LSSP-PCR technique with the $S 35 \mathrm{G}^{*}$ primer $\left(5^{\prime}\right.$-AAA TAA TGT ACG GGG GAG AT- $3^{\prime}$ ). A volume of $1 \mu \mathrm{L}$ of diluted DNA was added to the $10 \mu \mathrm{L}$ of the reaction mixture containing $6.38 \mu \mathrm{L}$ of sterile milli-Q water, $2.0 \mu \mathrm{L}$ of sample buffer, $0.2 \mu \mathrm{L}$ of each deoxynucleotide (dATP, dCTP, dGTP, and dTTP-Sigma, St. Louis, MO, USA), $0.1 \mu \mathrm{L}$ of the S35G * primer $(450 \mu \mathrm{M})$, and $0.32 \mu \mathrm{L}$ of Taq DNA polymerase (Go Taq-Promega) (18). Amplification occurred under the following conditions: an initial DNA denaturation stage at $95^{\circ} \mathrm{C}$ for $5 \mathrm{~min}$, annealing at $30^{\circ} \mathrm{C}$ 
for $1 \mathrm{~min}$, and extension at $72^{\circ} \mathrm{C}$ for $1 \mathrm{~min}$, followed by 40 amplification cycles consisting of a denaturation step at $94^{\circ} \mathrm{C}$ for $1 \mathrm{~min}$, one cycle of annealing at $30^{\circ} \mathrm{C}$ for $1 \mathrm{~min}$, followed by a final extension step at $72^{\circ} \mathrm{C}$ for $10 \mathrm{~min}$. The LSSP-PCR products were separated in $6 \%$ polyacrylamide gel electrophoresis and revealed with $\mathrm{NaOH}$ and formaldehyde after silver staining (19). After photo documentation the differences in the patterns of band profiles were analyzed via bioinformatics tests.

\section{Bioinformatics Analysis}

The LSSP-PCR profiles were used to build a presence/absence matrix of each visualized band, allowing a similarity analysis to be built using NTSYSpc software. The relationships between T. cruzi strains were estimated using a dendrogram representative of the LSSP-PCR data. These were constructed based on the coefficient of association (20) and the analysis of unweighted peer groups [unweighted pair-group method analysis (UPGMA)] using Mega 6.04 Beta software. To estimate Shannon's diversity, the cophenetic correlation coefficient, heterozygosity by locus $(\mathrm{He})$, and principal coordinated analysis ( $\mathrm{PCoA})$ were performed using the GenAlEx 6.5 software. In this case, a genetic distance matrix was built. This calculation of genetic distances took place in pairs for binaries. Data followed the methods of Huff and collaborators (21), wherein any comparison with the same state generates a value of 0 (for both 0 vs. 0 comparisons and comparisons 1 vs. 1$)$, while any comparison of different states (0 vs. 1 or 1 vs. 0 ) generates a value of 1 .

\section{Ethical Approval}

This study was approved by the Human Research Ethics Committee of the Vall d'Hebron University Hospital. All patients who agreed to participate in the study signed an informed consent form.

\section{RESULTS}

\section{Patient Characteristics}

This study included 27 patients with chronic ChD, identified via positive serology (IgG anti-T. cruzi) and real-time PCR for $\mathrm{ChD}$, who were clinically managed at the Infectious Disease Clinic of the Vall d'Hebron University Hospital, Barcelona, Spain between 2015 and 2019. All patients reside in Barcelona, Spain, and are immigrants from Bolivia, 8/27 (29.6\%) being male and $19 / 27(70.4 \%)$ female (Table 1$)$. The mean age of the patients was $47.1 \pm 12.44$ years (Table 1). Taking into account clinical features, echocardiography (ECG) and radiological exams, 17/27 (62.9\%) of the patients, presented the indeterminate form of $\mathrm{ChD}$ and $10 / 27(37.1 \%)$ the cardiomyopathy form. All patients with Chagas cardiomyopathy' were categorized in stage B1 of clinical evolution according to the European Society of Cardiology (13). No patient had the digestive, nervous, or mixed clinical forms of ChD.

\section{Intra DTU TcV Genetic Variability of Trypanosoma cruzi}

The LSSP-PCR analysis showed that the reaction amplified the $330 \mathrm{pb}$ fragment of the T. cruzi kDNA in all $27 \mathrm{DNA}$
TABLE 1 | General information of patients with Chagas disease involved in the study.

\begin{tabular}{|c|c|c|c|c|}
\hline Sample code & $\begin{array}{c}\text { Age } \\
\text { (years) }\end{array}$ & Gender & Clinical form & DTU \\
\hline 1 & 32 & $\mathrm{~F}$ & Cardiac & $\mathrm{TcV}$ \\
\hline 2 & 27 & $\mathrm{~F}$ & Indeterminate & $\mathrm{TcV}$ \\
\hline 3 & 43 & $M$ & Cardiac & $\mathrm{TcV}$ \\
\hline 4 & 65 & $\mathrm{~F}$ & Cardiac & $\mathrm{TcV}$ \\
\hline 5 & 68 & $\mathrm{~F}$ & Cardiac & $\mathrm{TcV}$ \\
\hline 6 & 39 & $M$ & Indeterminate & $\mathrm{TcV}$ \\
\hline 7 & 60 & $\mathrm{~F}$ & Indeterminate & $\mathrm{TcV}$ \\
\hline 8 & 41 & $M$ & Indeterminate & TcV \\
\hline 9 & 46 & $M$ & Indeterminate & $\mathrm{TcV}$ \\
\hline 10 & 38 & $\mathrm{~F}$ & Cardiac & $\mathrm{TcV}$ \\
\hline 11 & 56 & $\mathrm{~F}$ & Indeterminate & $\mathrm{TcV}$ \\
\hline 12 & 67 & $\mathrm{~F}$ & Indeterminate & TcV \\
\hline 13 & 35 & $M$ & Indeterminate & $\mathrm{TcV}$ \\
\hline 14 & 44 & $\mathrm{~F}$ & Indeterminate & $\mathrm{TcV}$ \\
\hline 15 & 56 & $\mathrm{~F}$ & Indeterminate & $\mathrm{TcV}$ \\
\hline 16 & 28 & $M$ & Indeterminate & TcV \\
\hline 17 & 27 & $\mathrm{~F}$ & Indeterminate & $\mathrm{TcV}$ \\
\hline 18 & 39 & $\mathrm{~F}$ & Indeterminate & $\mathrm{TcV}$ \\
\hline 19 & 37 & $\mathrm{~F}$ & Indeterminate & $\mathrm{TcV}$ \\
\hline 20 & 56 & $\mathrm{~F}$ & Indeterminate & $\mathrm{TcV}$ \\
\hline 21 & 60 & $\mathrm{~F}$ & Cardiac & $\mathrm{TcV}$ \\
\hline 22 & 53 & $\mathrm{~F}$ & Cardiac & $\mathrm{TcV}$ \\
\hline 23 & 56 & $\mathrm{~F}$ & Indeterminate & $\mathrm{TcV}$ \\
\hline 24 & 44 & $M$ & Cardiac & TcV \\
\hline 25 & 62 & $M$ & Cardiac & $\mathrm{TcV}$ \\
\hline 26 & 43 & $\mathrm{~F}$ & Cardiac & $\mathrm{TcV}$ \\
\hline 27 & 50 & $\mathrm{~F}$ & Indeterminate & $\mathrm{TcV}$ \\
\hline
\end{tabular}

F, Female; M, Male; TcV, T. cruzi DTU; DTU, Discrete Typing Unit.

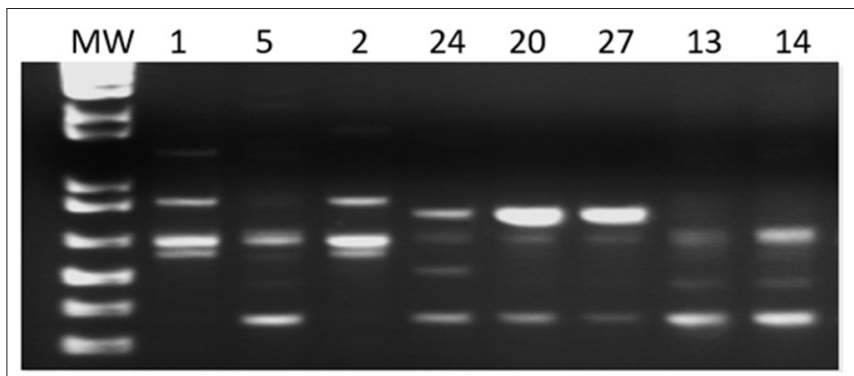

FIGURE 1 | Gel representative of the amplified products of the LSSP-PCR. MW-Molecular Weight: $1 \mathrm{~kb} ; 1$, 5, 2, 24, 20, 27, 13, and 14 patient samples.

samples from patients infected with TcV DTU. After the second amplification cycle, a total of 432 fragments were detected, and the products amplified were evaluated. The sizes of the bands varied between 80 and 1,500 bp (Figure 1). Sixteen profiles of the amplified products of the LSSP-PCR were obtained and only one $(6.25 \%)$ was shared among all samples. The percentage of polymorphic loci was $93.84 \%$, demonstrating the 


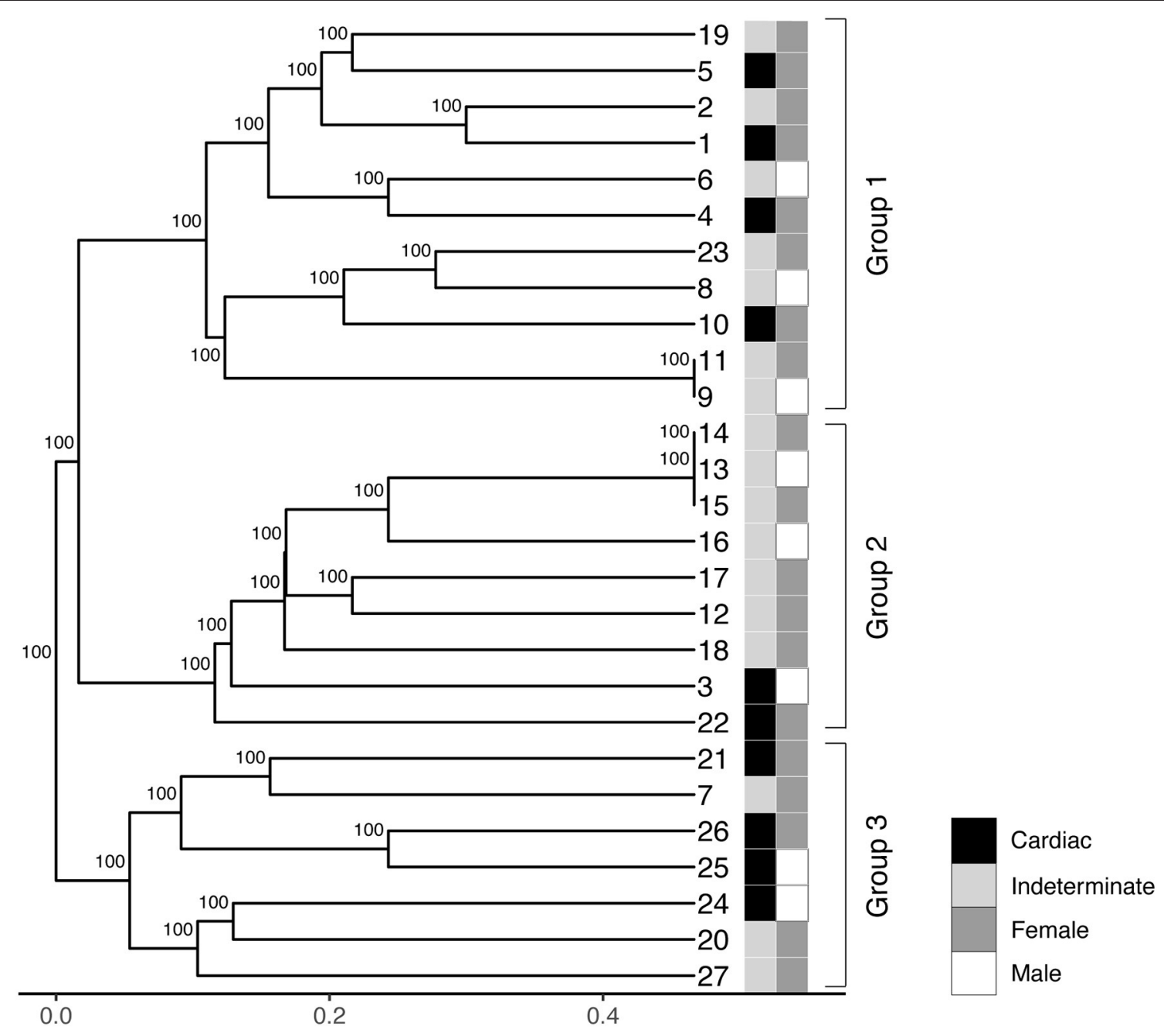

FIGURE 2 | Phenogram containing UPGMA (unweighted pair-group method analysis) of the 27 samples of $T$. cruzi belonging to DTU TcV. The numbers on the horizontal scale were obtained from the similarity coefficient of data. Different colors represent the clinical forms (indeterminate and cardiac) and gender of each patient (male or female).

existence of a high rate of genetic variability among the samples. The cophenetic correlation coefficient, which verifies that the dendrogram preserved the distances in pairs between the original unmodeled data points, obtained a value of 0.851 , confirming the high representation of the similarity matrices in the dendrogram. The UPGMA dendrogram distinguished T. cruzi DTU TcV samples into three distinct groups (Figure 2). Patients with the indeterminate form of $\mathrm{ChD}$ were clearly grouped in two groups (group 1 and 2) of the dendrogram, what showed that the genomes of these protozoa share certain alleles that may indicate common genetic characteristics and less intraspecific variability. For patients with the cardiac form of $\mathrm{ChD}$, no sharing of distinct alleles was observed, indicating a higher rate of intraspecific genetic variability and complexity (Figure 2).

The DICE similarity coefficient corroborated the data contained in the dendrogram and UPGMA. This analysis was used to assess the variability of alleles in each sample in the range 0 to \pm 1 (Figure 3 ). When comparing DNA samples from patients with the Indeterminate clinical form of Chagas disease, it was observed that the color intensity in Figure 3 tends to become darker, approaching the number 1 staining score. This may indicate a high degree of similarity between these samples.

The analysis of the principal coordinated analysis (PCoA) in the two axes demonstrated $80.30 \%(35.1+45.2 \%)$ of the variability between the components (Figure 4) and, in total, three distinct groups were formed, as shown in the UPGMA dendrogram. The average expected $\mathrm{He}$ was 0.296, indicative of moderate-high genetic diversity among the 27 samples. In addition, Shannon Weaver's diversity index $\left(\mathrm{H}^{\prime}\right.$ $=3,159$ ), a quantitative measure that defines the genetic diversity of species taking into account their variability, was also considered moderate to high. This assessment was used to describe the richness of the intra-DTU $\mathrm{TcV}$ variability of T. cruzi. 


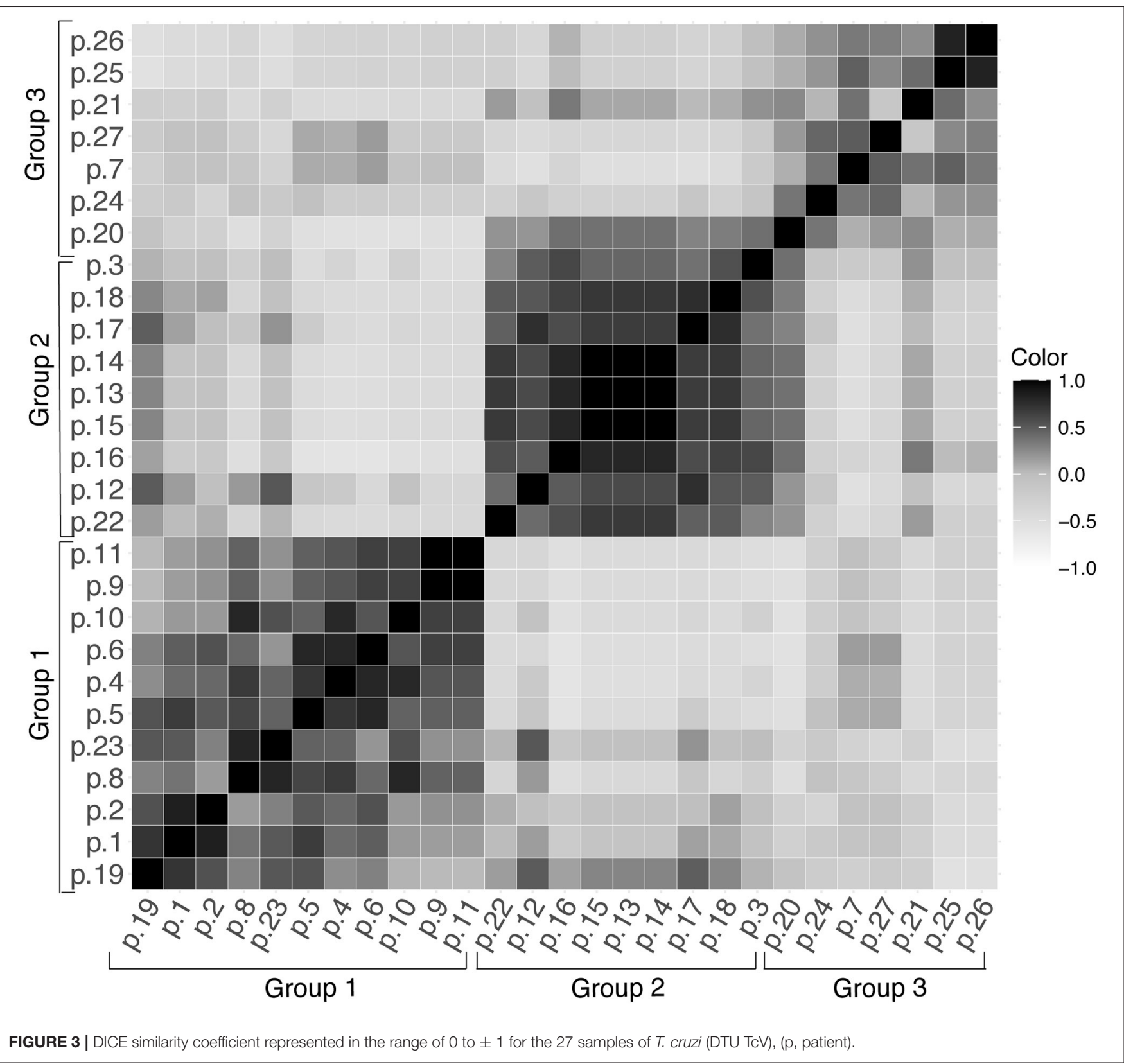

\section{DISCUSSION}

Trypanosoma Cruzi specie includes heterogeneous subpopulations that circulate in both domestic and wild cycles (22), and this diversity can be observed at the morphological (23), biological, antigenic (24), and genetic (5, 25) levels. Moreover, T. cruzi is currently subdivided into seven distinct genetic groups (DTUs TcI-TcVI and Tcbat) (4), and each DTU has its own characteristics (3). In order to better understand the disease in each geographical region it is necessary to study the molecular epidemiology of this parasite, inherently related to the main biological characteristics, which consequently have clinical implications on Chagas disease clinical features and evolution.
$\mathrm{ChD}$ is endemic in Latin America; however, the epidemiology of this infection has changed, mainly due to recent population migration for countries of distinct continents. At present, $\mathrm{ChD}$ is an important public health problem in other non-endemic regions, such as Europe (8). Immigration to Europe from Latin American countries has increased steadily over the last 2 years, especially to southern European countries, such as Spain and Italy. More recently, there is evidence for Latin American immigration to northern countries in Europe as well $(10,26)$. These population movements have increased the occurrence of $\mathrm{ChD}$ in these countries (9), since a considerable proportion of Latin American immigrants are chronically infected with T. cruzi, added to the occurrence of autochthone 


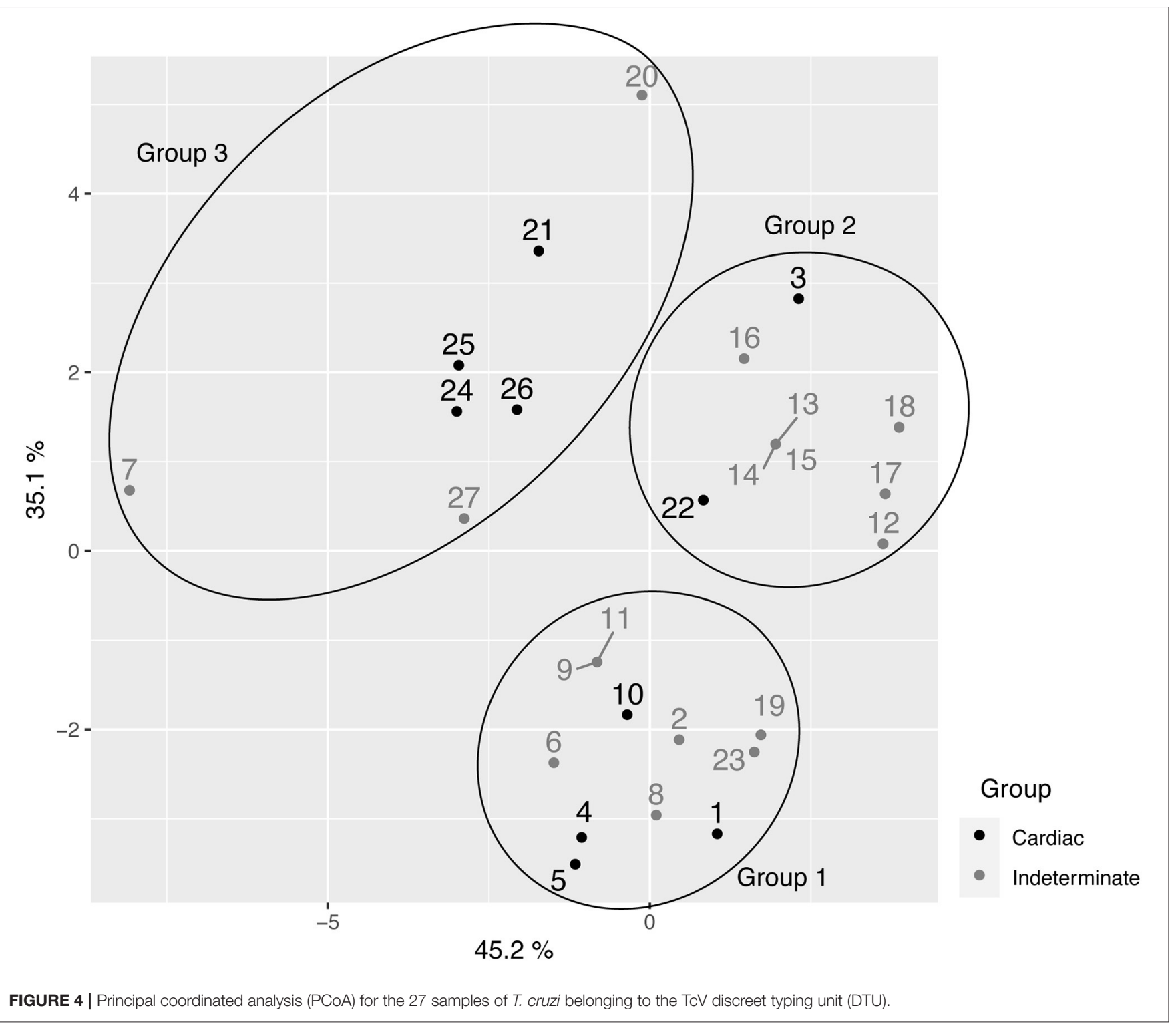

cases transmitted by mechanisms independent to triatomine vectors. Consequently, the number of reported cases of $\mathrm{ChD}$ with or without cardiac involvement has increased dramatically in recent years, especially in European countries, such as Spain, Italy, and Switzerland, where most Latino immigrants have settled $(27,28)$. Thus, studies aiming to evaluate the possible association between the intraspecific genetic variability of T. cruzi with the specific clinical forms of $\mathrm{ChD}$ are necessary.

It is known that DTU TcV is closely related to the domestic cycle of $\mathrm{ChD}$ associated with human disease in countries such as Argentina, Bolivia, Chile and Paraguay (6). This genotype is related to the presentation of clinical cardiac and digestive symptoms in patients from countries in the southern cone and little is known about their natural mammalian reservoirs (3). Previous studies have demonstrating the existence of genetic variability within TcI (29) and TcII (30) isolates. In the present study, a pioneering moderate-high rate of genetic variability within DTU TcV of T. cruzi in a specific population of Bolivian immigrants in Spain was assessed by LSSP-PCR. Furthermore, an association was detected between the indeterminate form of $\mathrm{ChD}$ and sharing certain alleles present in the parasite's genome.

It is relevant to emphasize that the LSSP-PCR methodology had been described and widely used to identify $T$. cruzi underlines before the first genotyping criteria emerged in 2009 (31-33). Burgos and collaborators used this methodology to evaluate the decrease of certain subclasses of the parasite kDNA minicircles in the peripheral blood and brain tissue of a patient infected with human immunodeficiency virus and with T. cruzi (TcII) during treatment for Chagas disease (34). Similarly, Costales and collaborators employed LSSPPCR to investigate the presence of polyclonal infection of the parasite belonging to the $\mathrm{TCI}$ genotype in a cardiomyopathic 
patient with reactivation of the infection after heart transplantation (35).

Lages-Silva et al. (30) also tried to establish the association of intra-DTU genetic variability with the different clinical manifestations of patients infected with T. cruzi. It is worth mentioning that the authors used the same molecular technique (LSSP-PCR) employing different genes, and as in the present study, they were unable to detect an effective correlation, what demonstrated the need to search for genetic targets that are increasingly intrinsic in the parasite's genome. In the work involving DTU TcI (29), the study group sought to assess the association between the TcI genotype and the home and wild distribution of the genetic lineage in its hosts and biological aspects of the strains. It is worth mentioning that the TcV DTU is a hybrid strain, originating from several hybridization processes between TcI and TcII, with loss of heterozygosity between the progeny to produce TcIII and TcIV, followed by a second more recent hybridization event between TcII and TcIII to produce both, TcV and TcVI (36).

Lima and collaborators evaluated a family with two generations of patients with chronic $\mathrm{ChD}$ infected with DTU TcII, and attempted to establish the DTU/clinical forms correlation. However, no satisfactory results were obtained, possibly due to the low number of clinical samples. Despite of similarly to the present study, in addition, they reported low genetic variability/diversity in samples of the parasite belonging to the TcII genotype (37).

In our study the UPGMA analysis of the samples demonstrated the existence of three large groups within the T. cruzi $\mathrm{TcV}$ genotype, including a high rate of intraspecific genetic variability/diversity of this DTU. Similar data were obtained by some of us using T. cruzi DTU TcII and TcVI genotypes (38). We demonstrated, through UPGMA and PCoA of random amplification of polymorphic DNA, the existence of a high rate of genetic variability within DTU TcII and TcVI of $T$. cruzi in samples from patients with chronic $\mathrm{ChD}$ residing in an important endemic region of Minas Gerais state, Brazil.

Additionally, in accordance with the UPGMA results of our study, Macchiaverna and collaborators showed that the sequencing data of the T. cruzi TcMK (mevalonate kinase) gene in clinical samples from chronic patients in Argentina, revealed a low rate of genetic variability within the DTU TcV, and showing apparently two robust subgroups of isolates (39).

Few studies have undertaken a more detailed intra-DTU approach in an attempt to detect the appropriate correlations with the clinical forms of $\mathrm{ChD}$ presented by the patients. A more common approach has been to search correlation between T. cruzi DTUs and the clinical forms of ChD. However, it is reasonable to speculate that small genetic modifications or alterations in parasite genomes at intra-DTU level may be more related to the induction of distinct clinical manifestations of this disease, and even responses to a specific treatment against the T. cruzi, favoring a better understanding of the clinical and epidemiological aspects of this disease in endemic and nonendemic regions.

Therefore, knowing the genetic variability of T. cruzi intra$\mathrm{DTU} \mathrm{TcV}$ in immigrant patients with chronic $\mathrm{ChD}$ residing in
Barcelona, Spain, is crucial to understanding the public health implications of $\mathrm{ChD}$ in European countries. Improving this understanding could contribute for the adequate design and planning of more effective public health interventions to improve the health of the immigrants and control the vertical transmission of $\mathrm{ChD}$, which is a serious problem in Europe nowadays.

\section{CONCLUSIONS}

This study demonstrated the existence of a moderate to high rate of intra-DTU $\mathrm{TcV}$ variability in $T$. cruzi, in a specific population of Bolivian immigrants in Spain. Being demonstrated association of sharing of certain alleles of the parasite with the absence of clinical manifestations in patients harboring the indeterminate clinical form of $\mathrm{ChD}$, a trend to be assessed in a larger population. The information provided in this study could affect the planning of more effective public health interventions to improve the health of immigrants, vertical transmission control, and improvement of $\mathrm{ChD}$ treatment in countries with predominance of infection by $\mathrm{TcV}$ genotype. The results of this study support the need to search for increasingly intrinsic and specific targets in the genome of T. cruzi to be correlated with its main biological properties and clinical features in patients with chronic ChD.

\section{DATA AVAILABILITY STATEMENT}

The original contributions presented in the study are included in the article/supplementary material, further inquiries can be directed to the corresponding author/s.

\section{ETHICS STATEMENT}

The studies involving human participants were reviewed and approved by Human Research Ethics Committee of the Vall d'Hebron University Hospital. The patients/participants provided their written informed consent to participate in this study.

\section{AUTHOR CONTRIBUTIONS}

MO, ES, AS, and IM: conceptualization. MO, ES, and IM: data curation. MO: formal analysis, validation, and writingoriginal draft. $\mathrm{MO}$ and JM-N: funding acquisition. MO, ML, and JS: investigation. MO, ES, and AS: methodology. JM-N and IM: project administration and supervision. MO, ES, ML, and IM: resources. MO, ES, AS, ML, JM-N, and IM: visualization. MO, MS, ML, JS, JM-N, and IM: writing - review and editing. All authors contributed to the article and approved the submitted version.

\section{FUNDING}

This work was supported by São Paulo Research Foundation (FAPESP)- fapesp.br/en (Grant No. 2018/22093-4), São Paulo Research Foundation (FAPESP)- fapesp.br/en (Grant No. 
2019/11943-0), São Paulo Research Foundation (FAPESP)fapesp.br/en (Grant No. 2016/25403-9), and Universitat Autònoma de Barcelona, Vall d'Hebron University Hospital, PROSICS Barcelona, Spain.

\section{REFERENCES}

1. Rassi A, Rassi A, Marcondes de Rezende J. American trypanosomiasis (Chagas disease). Infect Dis Clin North Am. (2012) 26:275-91. doi: 10.1016/j.idc.2012.03.002

2. WHO. Chagas Disease (American trypanosomiasis). Fact sheet No. 340. WHO (2018).

3. Zingales B. Trypanosoma cruzi genetic diversity: something new for something known about Chagas disease manifestations, serodiagnosis and drug sensitivity. Acta Trop. (2018) 184:38-52. doi: 10.1016/j.actatropica.2017.09.017

4. Zingales B, Andrade SG, Briones MRS, Campbell DA, Chiari E, Fernandes O, et al. A new consensus for Trypanosoma cruzi intraspecific nomenclature: second revision meeting recommends TcI to TcVI. Mem Inst Oswaldo Cruz. (2009) 104:1051-4. doi: 10.1590/S0074-02762009000700021

5. Tibayrenc M. Genetic subdivisions within Trypanosoma cruzi (discrete typing units) and their relevance for molecular epidemiology and experimental evolution. Kinetoplastid Biol Dis. (2003) 2:12. doi: 10.1186/1475-9292-2-12

6. Zingales B, Miles MA, Campbell DA, Tibayrenc M, Macedo AM, Teixeira MMG, et al. The revised Trypanosoma cruzi subspecific nomenclature: rationale, epidemiological relevance and research applications. Infect Genet Evol. (2012) 12:240-53. doi: 10.1016/j.meegid.2011.12.009

7. Requena-Méndez A, Aldasoro E, de Lazzari E, Sicuri E, Brown M, Moore DAJ, et al. Prevalence of chagas disease in Latin-American migrants living in Europe: a systematic review and meta-analysis. PLoS Negl Trop Dis. (2015) 9:e0003540. doi: 10.1371/journal.pntd.0003540

8. Rechel B, Mladovsky P, Ingleby D, Mackenbach JP, McKee M. Migration and health in an increasingly diverse Europe. Lancet. (2013) 381:1235-45. doi: 10.1016/S0140-6736(12)62086-8

9. Pérez-Molina JA, Molina I. Chagas disease. Lancet. (2018) 391:82-94. doi: 10.1016/S0140-6736(17)31612-4

10. Basile L, Jansà JM, Carlier Y, Salamanca DD, Angheben A, Bartoloni A, et al. Chagas disease in european countries: the challenge of a surveillance system. Eurosurveillance. (2011) 16:3. doi: 10.2807/ese.16.37.19968-en

11. Muñoz J, Coll O, Juncosa T, Vergés M, Pino M Del, Fumado V, et al. Prevalence and vertical transmission of Trypanosoma cruzi infection among pregnant latin american women attending 2 maternity clinics in barcelona, spain. Clin Infect Dis. (2009) 48:1736-40. doi: 10.1086/599223

12. de Oliveira MT, Sulleiro E, Gimenez AS, de Lana M, Zingales B, da Silva JS, et al. Quantification of parasite burden of Trypanosoma cruzi and identification of discrete typing units (Dtus) in blood samples of latin american immigrants residing in Barcelona, Spain. PLoS Negl Trop Dis. (2020) 14:e0008311. doi: 10.1371/journal.pntd.0008311

13. Avila HA, Sigman DS, Cohen LM, Millikan RC, Simpson L. Polymerase chain reaction amplification of Trypanosoma cruzi kinetoplast minicircle DNA isolated from whole blood lysates: diagnosis of chronic Chagas' disease. $\mathrm{Mol}$ Biochem Parasitol. (1991) 48:11-21. doi: 10.1016/0166-6851(91)90116-n

14. Britto C, Cardoso MA, Wincker P, Morel CM. A simple protocol for the physical cleavage of Trypanosoma cruzi kinetoplast DNA present in blood samples and its use in polymerase chain reaction (PCR)-based diagnosis of chronic Chagas disease. Mem Inst Oswaldo Cruz. (1993) 88:171-2. doi: 10.1590/s0074-02761993000100030

15. Dias JCP, Ramos AN, Gontijo ED, Luquetti A, Shikanai-Yasuda MA, Coura JR, et al. Aspectos Gerais da epidemiologia da doença de chagas com especial atenção ao Brasil. Epidemiol Serv Saude Rev Sist Unico Saude Bras. (2016) 25:7-86. doi: 10.5123/S1679-49742016000500002

16. Mora G. Chagas cardiomyopathy. E J Cardiol Pract? (2016) 14:31-28. https:// www.escardio.org/Journals/E-Journal-of-Cardiology-Practice/Volume-14/ Chagas-cardiomyopathy

\section{ACKNOWLEDGMENTS}

We thank Pilar Alcubilla for her technical support and Mercedes Guerrero Murillo for bioinformatics analysis.

17. Vago AR, Macedo AM, Oliveira RP, Andrade LO, Chiari E, Galvão LMC, et al Kinetoplast DNA signatures of Trypanosoma cruzi strains obtained directly from infected tissues. Am J Pathol. (1996) 149:2153-59.

18. Gomes ML, Macedo AM, Vago AR, Pena SDJ, Galvão LMC, Chiari E. Trypanosoma cruzi: optimization of polymerase chain reaction for detection in human blood. Exp Parasitol. (1998) 88:28-33. doi: 10.1006/expr.1998.4191

19. Santos FR, Pena SDJ, Epplen JT. Genetic and population study of a Ylinked tetranucleotide repeat DNA polymorphism with a simple non-isotopic technique. Hum Genet. (1993) 90:655-6. doi: 10.1007/BF00202486

20. Dice LR. Measures of the amount of ecologic association between species. Ecology. (1945) 26:297-302. doi: 10.2307/1932409

21. Huff DR, Peakall R, Smouse PE. RAPD variation within and among natural populations of outcrossing buffalograss [Buchloë dactyloides (Nutt.) Engelm.]. Theor Appl Genet. (1993) 86:927-34. doi: 10.1007/BF00211043

22. Tibayrenc M, Ward P, Moya A, Ayala FJ. Natural populations of Trypanosoma cruzi, the agent of Chagas disease, have a complex multiclonal structure. Proc Natl Acad Sci USA. (1986) 83:115-9. doi: 10.1073/pnas.83.1.115

23. Brener Z, Chiari E. Varia C Oes morfol'ogicas observadas em diferentes amostras DE. Rev Inst Med Trop São Paulo. (1963) 19:220-224.

24. Maguire JH, Hoff R, Sleigh AC, Mott KE, Ramos NB, Sherlock IA. An outbreak of Chagas' disease in southwestern Bahia, Brazil. Am J Trop Med Hyg. (1986) 35:931-6. doi: 10.4269/ajtmh.1986.35.931

25. Tibayrenc M, Ayala FJ. The population genetics of Trypanosoma cruzi revisited in the light of the predominant clonal evolution model. Acta Trop. (2015) 151:156-65. doi: 10.1016/j.actatropica.2015.05.006

26. Gascon J, Bern C, Pinazo MJ. Chagas disease in Spain, the United States and other non-endemic countries. Acta Trop. (2010) 115:22-7. doi: 10.1016/j.actatropica.2009.07.019

27. Jackson Y, Gétaz L, Wolff H, Holst M, Mauris A, Tardin A, et al. Prevalence, clinical staging and risk for blood-borne transmission of chagas disease among Latin American migrants in Geneva, Switzerland. PLoS Negl Trop Dis. (2010) 4:e592. doi: 10.1371/journal.pntd.0000592

28. Coura JR, Vias PA. Chagas disease: a new worldwide challenge. Nature. (2010) 465:S6-7. doi: 10.1038/nature09221

29. León CM, Hernández C, Montilla M, Ramírez JD. Retrospective distribution of Trypanosoma cruzi I genotypes in Colombia. Mem Inst Oswaldo Cruz. (2015) 110:387-93. doi: 10.1590/0074-02760140402

30. Lages-Silva E, Ramírez LE, Pedrosa AL, Crema E, Da Cunha Galvão LM, Pena SDJ, et al. Variability of kinetoplast DNA gene signatures of Trypanosoma cruzi II strains from patients with different clinical forms of Chagas' disease in Brazil. J Clin Microbiol. (2006) 44:2167-71. doi: 10.1128/JCM.02124-05

31. Vago AR, Andrade LO, Leite AA, d'Ávila Reis D, Macedo AM, Adad SJ, et al., Filho GB, Pena SDJ. Genetic characterization of Trypanosoma cruzi directly from tissues of patients with chronic chagas disease: differential distribution of genetic types into diverse organs. Am J Pathol. (2000) 156:1805-9. doi: 10.1016/S0002-9440(10)65052-3

32. Franco DJ, Vago AR, Chiari E, Meira FCA, Galvão LMC, Machado CRS. Trypanosoma cruzi: mixture of two populations can modify virulence and tissue tropism in rat. Exp Parasitol. (2003) 104:54-61. doi: 10.1016/S0014-4894(03)00119-X

33. Segatto M, Rodrigues CM, Machado CR, Franco GR, Pena SDJ, Macedo AM. LSSP-PCR of Trypanosoma cruzi: how the single primer sequence affects the kDNA signature. BMC Res Notes. (2013) 6:174. doi: 10.1186/1756-0500-6-174

34. Burgos JM, Begher SB, Freitas JM, Bisio M, Duffy T, Altcheh J, et al. Molecular diagnosis and typing of Trypanosoma cruzi populations and lineages in cerebral chagas disease in a patient with AIDS. Am J Trop Med Hyg. (2005) 73:1016-8. doi: 10.4269/ajtmh.2005.73.1016

35. Costales JA, Kotton CN, Zurita-Leal AC, Garcia-Perez J, Llewellyn MS, Messenger LA, et al. Chagas disease reactivation in a heart transplant patient 
infected by domestic Trypanosoma cruzi discrete typing unit i (TcIDOM). Parasit Vect. (2015) 8:435. doi: 10.1186/s13071-015-1039-3

36. Freitas JM, Augusto-Pinto L, Pimenta JR, Bastos-Rodrigues L, Gonçalves VF, Teixeira SMR, et al. Ancestral genomes, sex, and the population structure of Trypanosoma cruzi. Plos Pathog. (2006) 2:e24. doi: 10.1371/journal.ppat.0020024

37. Lima APB, de Oliveira MT, Silva RR, Torres RM, Veloso VM, de Lana $M$, et al. Evaluation of parasite and host genetics in two generations of a family with Chagas disease. Parasitol Res. (2018) 117:3009-13. doi: 10.1007/s00436-018-5969-5

38. De Oliveira MT, MacHado De Assis GF, Oliveira E Silva JCV, MacHado EMM, Da Silva GN, Veloso VM, et al. Trypanosoma cruzi Discret Typing Units (TcII and TcVI) in samples of patients from two municipalities of the Jequitinhonha Valley, MG, Brazil, using two molecular typing strategies. Parasites and Vectors. (2015) 8: doi: 10.1186/s13071-015-1 161-2
39. Macchiaverna NP, Enriquez GF, Buscaglia CA, Balouz V, Gürtler RE, Cardinal MV. New human isolates of Trypanosoma cruzi confirm the predominance of hybrid lineages in domestic transmission cycle of the Argentinean Chaco. Infect Genet Evol. (2018) 66:229-35. doi: 10.1016/j.meegid.2018.10.001

Conflict of Interest: The authors declare that the research was conducted in the absence of any commercial or financial relationships that could be construed as a potential conflict of interest.

Copyright $\odot 2021$ Oliveira, Sulleiro, Silva, Silgado, de Lana, da Silva, Molina and Marin-Neto. This is an open-access article distributed under the terms of the Creative Commons Attribution License (CC BY). The use, distribution or reproduction in other forums is permitted, provided the original author(s) and the copyright owner(s) are credited and that the original publication in this journal is cited, in accordance with accepted academic practice. No use, distribution or reproduction is permitted which does not comply with these terms. 